\title{
15 Contextual determinants of fear of crime in public transit
}

\section{An Ecological Momentary Assessment (EMA) pilot study}

\author{
Yasemin Irvin-Erickson, \\ Ammar A. Malik \\ and Faisal Kamiran
}

\subsection{Introduction}

Public transit users are particularly vulnerable to the negative consequences of fear of crime. In public transit settings, when fear of crime outpaces actual crime rates, a potentially significant number of people will not use or reduce use of public transit on account of fear (Badiora, Ojewale, \& Okunola, 2015). Negative consequences of fear of crime necessitate identification of context-specific conditions that trigger fear in public transit settings. This information can inform policy decisions in important ways in relation to the design and management of public spaces and public transit, and community safety practices in and around public transit.

The purpose of our pilot study presented in this chapter is to demonstrate the utility of Ecological Momentary Assessments (EMAs) to identify the relationship between transit specific contextual factors and fear of crime. EMAs are a data collection method in which information about individuals' experiences, emotions, and behaviors is collected in real-time via smart devices, as individuals go about their lives (Raento, Oulasvirta, \& Eagle, 2009).

In our pilot study in Lahore, Pakistan, we deployed EMAs through a mobile survey app and we collected real-time and near real-time context-specific data on fear of crime. Specifically, with this innovative approach, we conducted our pilot study to answer the following research question: what vehicle, station/stop, and environment specific factors might be affecting public transit users' fear of crime? The methodology piloted in our study can help advance the theoretical explanations of fear of crime in public settings, and especially in public transit settings. Our study methodology and results can also provide important insights and guidelines to researchers and practitioners in the fields of criminology, city planning, public safety, and transportation.

\subsection{Contextual determinants of fear of crime}

Individuals' observations of built and social environments as they go about their lives could affect their cognition of their risk of victimization and trigger 
feelings of worry, which may be altogether expressed as fear of crime. Elements of physical environment have been the most frequently studied aspect of places in the literature as various researchers have successfully shown the contextual element of people's fear and perceived risk (Lorenc et al., 2012, 2013; Pain, 2000).

Among the many theories that have been used to explain fear of crime, theories of social disorder have been the ones that most directly focus on the role of the built and social environments in shaping people's fear of crime and perceived risk of crime. Social disorder theories posit that disorderly activities and signs of disorder in communities creates fear of crime. Specifically, Broken Windows Theory (Wilson \& Kelling, 1982) suggests that perceptions of physical and social deterioration in individuals' environment can increase their sense of vulnerability and then result in a higher fear of crime among residents, reduced social control, and eventually an increase in crime. The propositions of social disorder theories about this relationship between perceived physical and social incivilities and fear and perceived risk of crime have been well supported by existing research (Lorenc et al., 2012).

For instance, physical signs of problems and neglect in the immediate environment such as graffiti, vacant and vandalized buildings, and abandoned cars have been associated with increased levels of fear. Furthermore, problems in the social environment such as the presence of disorderly individuals (i.e., people under the influence, people begging, homeless individuals) or signs of disorderly behavior such as the presence of litter and drug paraphernalia have also been closely linked with people's increased fear of crime (Cozens, Neale, Whitaker, \& Hiller, 2003; Farrall, Jackson, \& Gray, 2009; Hale, 1996; Innes \& Jones, 2006; Liska, Lawrence, \& Sanchirico, 1982; LaGrange, Ferraro, \& Supancic, 1992; Skogan \& Maxfield, 1981; Vrij \& Winkel, 1991; Warr, 1990; Waters, Neale, \& Mears, 2007).

Lighting has also been frequently cited as a correlate of people's worry of victimization (Lindgren \& Nilsen, 2012; Nasar \& Jones, 1997; Pain, 1997; Painter 1989; Herbert \& Davidson, 1994). Finally, yet importantly, places with few people around (Burgess, 2002; Koskela \& Pain, 2000; Pain \& Townshend, 2002 ) and crowdedness at places (Patterson, 1985) can also induce increased levels of fear.

The different research studies we reviewed on the relationship between perceived physical incivilities and signs of disorder posit that there is a relationship between fear of crime, perceived risk of crime, and contextual factors. However, with the exception of two recent studies by Chataway, Hart, Coomber, and Bond (2017) and Chataway, Hart, and Bond (2019), no other studies to the best of our knowledge attempted to collect information about these contextual correlates of fear of crime in the immediate environment of individuals.

In 2017, Chataway et al. (2017) used a mobile phone survey application to send EMAs to a convenience sample of 20 students at an Australian university as the participants travelled close to 10 georeferenced areas in their 
study area over a three-month data collection period. The authors collected data on the following indicators: (1) the demographic information about the participants (which was collected only once when the participants first launched the app); and participants' perceptions of (2) worry, (3) likelihood of victimization, (4) consequences of victimization, (5) control over crime, (5) beliefs about the incidence of crime; and (6) social and physical environment. Although the authors of this study collected context-specific data on correlates of fear of crime, the worry measure utilized in this study was retrospective. The authors captured study participants' fear of victimization in the past month by asking them about their worry with a four-item response; "l" indicating that the respondent experienced worry "not once in the past month" and " 4 " indicating that the respondent experienced worry "everyday" in the past month. In the same study, to measure participants' perceptions about their immediate environments, the authors asked seven questions to capture respondents' perceptions of physical and social incivility. The respondents were asked how much of a problem they felt the following conditions were in their immediate environments: (1) vandalism/graffiti; (2) garbage in the streets; (3) dogs out of control; (4) drug use in the open; (5) drinking in the street; (6) teenagers hanging around, and (7) not enough things for young people to do.

The authors asked seven more questions to capture participants' perception of social cohesion in their immediate environment. Specifically, the participants were asked to what degree they agree with the following statements: (1) the people who live here can be relied upon to call the police if someone is acting suspiciously; (2) if any of the children or young people around here are causing trouble, local people will tell them; (3) if I sensed trouble whilst in this area, I could raise attention from people who live here for help; (4) this area has a close, tight-knit community; (5) this area is a friendly place to live; (6) this area is a place where local people look after each other; and (7) most people who live in this area trust one another. The results from this study showed that perceived social cohesion was a statistically significant correlate of fear of crime while perceived incivility was not. Looking at the direction of the relationship between these variables, although an increase in perceived social cohesion was observed to be associated with a decrease in the odds of worry about personal crime, an increase in perceived incivilities was associated with a decrease in the odds of worry about personal crime. Despite the statistical insignificance of the relationship between perceived incivilities and odds of worry, the direction of the relationship between the two is surprising. However, this study is limited in its exploration of the relationship between fear of crime and perception of social cohesion and incivilities since the authors collected immediate environment specific data only on participants' perception of incivilities and social cohesion, and not on their worry of victimization. In other words, the perception of incivilities and social cohesion represented the immediate environment while worry of crime did not.

A more recent study by Chataway et al. (2019) advanced upon the methodology of Chataway et al. (2017) by introducing real-time measures of 


\section{Tasemin Irvin-Erickson et al.}

fear of crime in their mobile data collection efforts. In this new study, the authors sent EMAs to 72 study participants in Queensland, Australia via a mobile survey application in a three-month data collection period. Similar to the Chataway and colleagues' 2017 study, the authors collected data on demographics of the study participants; participants' perceptions of worry, belief, consequences, control and likelihood of victimization; and participants' perceptions of incivilities and social cohesion in their immediate environment. The results from this new study showcased that, unlike the results from the Chataway and colleagues' 2017 study, an increased perception of lack of social cohesion and increased levels of physical incivility in a person's environment were both statistically significantly related with higher levels of perceived risk of victimization and worry about crime. While discussing these results, Chataway and colleagues (2019) emphasize the importance of distinguishing between retrospective (reflective on past) and transitionary (context-dependent/ real-time) assessments of fear and risk of victimization. This recent study further demonstrates the need for incorporation of EMA methods to capture context-specific and real-time information on fear of crime and perceived risk of victimization.

\subsection{Current study}

In this study, we piloted an EMA methodology to collect real-time information about contextual correlates of individuals' fear of victimization. Our methodology, including our mobile survey application app and pilot sample and study extent, is explained in detail in our forthcoming article (Irvin-Erickson et al., 2020). Our pilot study aims to add to the existing literature on fear of crime, by collecting context-specific data on individuals' public transit experiences and their fear of crime and perceived victimization risk at different stages of their journey, namely waiting at a public transit stop, walking to and from a public transit stop, and traveling in a vehicle.

\section{Methodology}

\section{Data}

The data for our pilot study was collected from a convenience sample of six adult students (three male, three female) enrolled at a university in Lahore, Pakistan over a four-day data collection period. Each of the pilot participants was assigned a travel route in Lahore and completed several EMAs in the data collection period (eight to nine surveys per participant a day over the course of four days). The pilot participants were prompted to complete their surveys via our custom-built mobile survey application as they came within 50 meters of one of the 26 georeferenced Bus Rapid Transit (BRT) stations in Lahore. Study participants were also encouraged to fill out surveys at any other times and places of their preference. Study participants were required to complete a 
training at the beginning of the pilot and were administered an informed consent protocol (for details of this training please see Irvin-Erickson et al., 2020). Participants were provided with a smart phone, a wireless data plan, and a modest daily allowance for food and drinks. Pilot participants completed a total of 220 EMA reports in the data collection period.

\section{The mobile survey application}

Our team developed a custom-built application to deploy our EMAs in Android smartphones. We were able to capture the time and location of EMAs submitted via the GPS capability of the smartphones. We were further able to push EMAs to our respondents as they came in close proximity of the BRT stations in the study extent using the same GPS capability. Although the main aim of the study was to capture real-time information about respondents' travel experiences and fear of crime, we also provided retrospective reporting options to our respondents to ensure respondents' safety in high-risk or uncomfortable situations.

If the respondent was prompted to complete an EMA (if they were pinged), they had two options: (a) they either completed their EMA in real time or (b) they clicked a "respond later" button in the app and completed the EMA later. In case "b", the app recorded both the time and location of the original EMA prompt, and the time and location of the later EMA submission.

If the respondent wanted to report an "ongoing" fear event: (a) they either clicked "Start Survey" button in the app and completed the EMA in real time or (b) they clicked a "respond later" button in the app and completed the EMA later. After conferral with our project's Institutional Review Board, pilot respondents were instructed not to complete surveys in real time while traveling in a public transit vehicle, and to only use "Report Later" and "Report Past Incident" options due to the increased victimization risk such observations in a vehicle in transit can pose to pilot participants.

Lastly, if the respondent wanted to report a "past" fear event, the respondent clicked "Start Survey" and "Report Past Incident" buttons in the app, indicated the time and location of fear incident; and completed the survey later. In this case, the app recorded both the time and location of fear event as indicated by the respondent, and the time and location of the later EMA submission. Out of the 220 EMAs submitted by the respondents, 47 EMAs (21 percent) were submitted with the "report later" option; three EMAs (1 percent) were submitted with the "report a past experience" option, 103 EMAs (47 percent) were reported in real-time in response to the pings from the app as respondents came in close proximity to one of the 26 georeferenced BRT stations, and 67 EMAs (31 percent) were reported un-prompted in real-time by the respondents. In instances where the respondents used the app's "report past incident" option, the time difference between the actual fear event and EMA submission time ranged between 12 and 32 minutes. 


\section{Fear of crime survey instrument}

We collected data on the following indicators using our survey instrument: (1) respondent's fear of crime; (2) respondent's perceived risk of victimization; (3) respondent's stage of journey; (4) respondent's observations about the immediate environment (i.e., indicators of physical incivility and crowdedness); (5) time and location of EMA submissions; and (6) time and location of fear experiences (if different from the time and location of EMA submissions).

\section{Dependent variables}

There is an ongoing debate in criminology about conceptualization and operationalization of fear of crime and perceived risk of victimization. These discussions include a critique of very broad measurements of fear of crime as both a feeling and cognition, and researchers' inability to discern between the two concepts. With the exception of the study by Chataway et al. (2019), there is no other study, to the best of our knowledge, that measured both fear of victimization and perceived risk of victimization in real-time.

In our study, we measured fear of crime by asking respondents at the moment (or at the time of the experience) how fearful they are (or they were) of becoming a victim of one of the four crimes: physical assault, mugging, pickpocketing or sexual harassment. The respondents rated their fear on a scale of $\mathrm{l}$ to $5, \mathrm{l}$ being "not at all fearful" and 5 being "extremely fearful." Similarly, we measured respondents' perceived risk of victimization by asking them at the moment (or at the time of the experience) how likely they perceive they are (or they were) to experience one of the four crimes. The respondent rated their likelihood on a scale of 1 to 5,1 being "not at all likely" and 5 being "extremely likely."

A series of correlation analyses we ran between fear and perceived risk measures at the beginning of our analysis revealed very strong and positive relationships between fear of crime and perceived risk of crime for each of the four crime categories included in our analysis. The crime categories included in our analysis were mugging, sexual harassment, pickpocketing, and physical assault, and Spearman's rho statistic between fear and perceived risk ranged between 0.8 and 0.9 for each of these four crime categories. Accordingly, we treated both fear of crime and perceived risk of victimization variables as dependent variables in our regression models and explored if similar context and situation specific factors account for respondents' ratings of fear of crime and perceived risk of victimization.

We created a composite index of fear by summing up the ratings for fear for each crime category. We calculated a reliability coefficient (Cronbach's alpha) to test the internal consistency of this composite fear scale (Cronbach's alpha $=0.86$ ). Additional confirmatory factor analysis of fear ratings for four different crime categories further produced one component with eigenvalues of 0.82 and above. 


\section{Independent variables}

\section{Crowdedness}

Crowdedness was a binary variable. If the respondent was traveling in a public transit vehicle and reported that the vehicle was crowded or there were not enough seats in the vehicle, this variable was coded as " 1 ", and otherwise coded as " 0 ". If the respondent was walking or waiting at a public transit stop and reported any one of the following conditions at the time of an observation, crowdedness was coded as " 1 " and if else, coded as " 0 ": there are many pedestrians; there are vendors around; the respondent is close to a street market, an entertainment theatre; or a taxi stand.

\section{Journey stage}

Journey stage was a nominal variable comprised of three categories: walking, waiting at a public transit stop, and traveling in a public transit vehicle.

\section{Perceived incivility}

Perceived incivility was a scale variable. This measure took a value between 0 and 5 based on how many of the following conditions the respondent reported if traveling on a vehicle: there are drunk people around; there is loud music playing in the vehicle; there are beggars in the vehicle; there are verbal altercations between people; vehicle is in poor condition, or based on how many of the following conditions the respondent reported if walking/waiting at a stop: I can see trash lying around; I hear loud music around, there are beggars around; there are drunk people around.

\section{Time of the day}

Time of the day was a nominal variable with two categories: rush hour and nonrush hour. Rush hour reports (reports between 7 a.m. and 11 a.m. and reports between 4 p.m. and 8 p.m.) were coded as "l" and the reports during non-rush hours (any time other than rush hours) were coded as "0". Almost 90 percent of the responses $(n=190)$ in our pilot study were received between $7 \mathrm{a} . \mathrm{m}$. and 5 a.m.

\subsection{Analysis and results}

We estimated an ordinal logistic regression to assess the relationship between crowdedness, journey stage, perceived incivility, time of the day, and fear of crime and perceived risk of victimization. We chose ordinal logistic regression because: (1) our dependent variables (i.e., fear of crime and perceived risk of crime) were ordinal variables; (2) our independent variables were categorical or continuous; (3) there was no multicollinearity between our independent 
variables (tolerance values were more than 0.1 and VIF values were less than 10). The unit of analysis in our study were the EMA reports from the respondents $(N=220)$.

Table 15.1 presents the descriptive statistics for the variables included in our ordinal regression models. For both fear of crime and perceived risk of victimization variables, the average rating across all EMA reports was close to 10 out of the max 20 points possible (Min: 4, Max: 18, $n=216$ ). In 87 percent of all EMA reports $(n=191)$, respondents indicated that they experienced a crowded environment. The average incivility rating across all EMAs was 1.8 (min: 0, max: $5, n=220$ ). The majority of the EMAs were submitted in relation to travel experiences while waiting at a stop (42 percent) or walking to or from a transit stop (38 percent).

Looking at the goodness of the fit of our fear of crime regression model, the statistically significant chi-square statistic along with the high pseudo R-square (chi-square $=105.612, p<0.001 ;$ Negalgarke $R$-square $=0.38$ ) indicated that, the full model was an improvement over the intercept only model. As illustrated in Table 15.2, the results from the ordinal logistic regression showed that incivility had a positive relationship with fear of crime. Specifically, for every unit of increase in perceived incivility in the EMAs, the odds of fear of crime was 2.2 times higher $(\operatorname{Exp}(B): 2.2 ; 95$ percent $C I, 1.83$ to 2.63$)$, a statistically significant effect (Wald statistic $=73.15, p<0.001$ ). In the same regression model, in comparison to EMAs in which respondents observed crowded situations, EMAs in which there was not a perception of crowdedness, the odds of fear of crime was 72 percent less $(\operatorname{Exp}(B): 0.28,95$ percent CI, 0.12 to 0.66$)$, a statistically significant effect (Wald statistic $=8.52, p<0.01$ ). Looking at the relationship between journey stage and fear of crime, in comparison to traveling in a transit vehicle, walking $(\operatorname{Exp}(B): 0.40$, Wald: $5.19, p<0.05)$ was a statistically significantly less fearful journey stage. Time of the day was not a statistically significant correlate of fear of crime.

Table 15.1 Descriptive statistics for the observations included in the OLS model

\begin{tabular}{lllll}
\hline Report characteristics & Average & Frequency & Minimum & Maximum \\
\hline Fear rating (0-20) & 9.65 & 216 & 4 & 18 \\
Perceived risk rating (0-20) & 9.56 & 216 & 4 & 18 \\
Crowdedness & & & & \\
Crowded & $87 \%$ & 191 & - & - \\
Not crowded & $13 \%$ & 29 & - & - \\
Incivilities (0-5) & 1.8 & 220 & 0 & 5 \\
Journey stage & & & & \\
Traveling on a vehicle & $20 \%$ & 44 & - & - \\
Waiting at a stop & $42 \%$ & 93 & - & - \\
Walking & $38 \%$ & 83 & - & - \\
Time of the dayRush hour & $29 \%$ & 63 & - & - \\
Non-rush hour & $71 \%$ & 157 & - & - \\
\hline
\end{tabular}


Table 15.2 Ordinal logistic regression results of fear of crime $(n=216)$

\begin{tabular}{|c|c|c|c|c|c|c|c|}
\hline & \multicolumn{7}{|c|}{ Fear of crime } \\
\hline & Estimate & $S E$ & Wald & p-value & $\operatorname{Exp}(B)$ & $\begin{array}{l}\text { Lower } \\
\text { bound }\end{array}$ & $\begin{array}{l}\text { Upper } \\
\text { bound }\end{array}$ \\
\hline Incivility & 0.79 & 0.09 & 73.15 & 0.000 & 2.20 & 1.83 & 2.63 \\
\hline $\begin{array}{l}\text { Not Crowded } \\
\text { (reference: } \\
\text { crowded) }\end{array}$ & -1.25 & 0.43 & 8.52 & 0.004 & 0.28 & 0.12 & 0.66 \\
\hline $\begin{array}{l}\text { Non-rush hour } \\
\text { (reference: rush } \\
\text { hour) }\end{array}$ & -0.48 & 0.27 & 3.11 & 0.078 & 0.61 & 0.36 & 1.05 \\
\hline $\begin{array}{l}\text { Walking (reference: } \\
\text { traveling in a } \\
\text { vehicle) }\end{array}$ & -0.89 & 0.39 & 5.19 & 0.023 & 0.40 & 0.18 & 0.88 \\
\hline $\begin{array}{l}\text { Waiting at a Stop } \\
\text { (traveling in a } \\
\text { vehicle) }\end{array}$ & -0.65 & 0.36 & 3.25 & 0.071 & 0.51 & 0.25 & 1.05 \\
\hline
\end{tabular}

The results of the ordinal logistic regression analysis of perceived risk of victimization were very similar to the fear of crime model. First, the goodness of the fit tests of our perceived risk of victimization model showed that our full model was an improvement over the intercept only model (chi-square $=105.612$, $p<0.001$; Negalgarke $R$-square $=0.39$ ). As illustrated in Table 15.3, the results from the ordinal logistic regression showed that incivility had a positive relationship with perceived risk of victimization. Specifically, for every unit of increase

Table 15.3 Ordinal logistic regression results of perceived risk of victimization $(n=216)$

\begin{tabular}{|c|c|c|c|c|c|c|c|}
\hline & \multicolumn{7}{|c|}{ Perceived risk of victimization } \\
\hline & Estimate & $S E$ & Wald & p-value & $\operatorname{Exp}(B)$ & $\begin{array}{l}\text { Lower } \\
\text { Bound }\end{array}$ & $\begin{array}{l}\text { Upper } \\
\text { Bound }\end{array}$ \\
\hline Incivility & 0.78 & 0.09 & 72.18 & 0.000 & 2.18 & 1.82 & 2.61 \\
\hline $\begin{array}{l}\text { Not crowded } \\
\text { (reference: } \\
\text { crowded) }\end{array}$ & -1.06 & 0.42 & 6.13 & 0.013 & 0.34 & 0.14 & 0.80 \\
\hline $\begin{array}{l}\text { Non-rush hour } \\
\text { (reference: } \\
\text { rush hour) }\end{array}$ & -0.53 & 0.27 & 3.82 & 0.051 & 0.58 & 0.34 & 1.00 \\
\hline $\begin{array}{l}\text { Walking (reference: } \\
\text { traveling } \\
\text { in a vehicle) }\end{array}$ & -1.01 & 0.39 & 6.66 & 0.010 & 0.36 & 0.16 & 0.78 \\
\hline $\begin{array}{l}\text { Waiting at a stop } \\
\text { (traveling } \\
\text { in a vehicle) }\end{array}$ & -0.62 & 0.36 & 2.91 & 0.088 & 0.53 & 0.26 & 1.09 \\
\hline
\end{tabular}


in perceived incivility in the EMAs, the odds of perceived risk of victimization was approximately 2.2 times higher $(\operatorname{Exp}(\mathrm{B}): 2.18 ; 95$ percent $\mathrm{CI}, 1.82$ to 2.61 ), a statistically significant effect (Wald statistic $=72.18, p<0.001$ ). In the same regression model, in comparison to EMAs in which respondents observed crowded situations, EMAs in which there was not a perception of crowdedness, the odds of perceived risk of victimization was 66 percent less $(\operatorname{Exp}(B): 0.34,95$ percent CI, 0.14 to 0.80 ), a statistically significant effect (Wald statistic $=6.13$, $p=0.01$ ). Looking at the relationship between journey stage and perceived risk of victimization, in comparison to traveling in a transit vehicle, walking $(\operatorname{Exp}(B): 0.36$, Wald: $6.66, p=0.01)$ was a statistically significantly less risky journey stage. In the perceived risk of victimization model, in comparison to EMAs during rush hours, for EMAs during non-rush hours, the odds of perceived risk of victimization was 42 percent less $(\operatorname{Exp}(B): 0.58,95$ percent $C I$, 0.34 to 1 ), a statistically significant effect (Wald statistic $=3.82, p=0.05$ ).

\subsection{Discussion}

Our study aimed to demonstrate the utility of EMAs deployed through smartphone technology to capture fear of crime and perceived risk of victimization in an individual's natural environment and different stages of their public transit journey. The results from our pilot study show that EMAs via smartphones can close the gap in the fear of crime literature by providing much necessary insight into spatio-temporal triggers of fear of crime at different stages of journey in public transit settings and other public settings. The findings from our study exemplifies how EMAs can (1) advance the measurement of fear of crime, perceived risk of crime, and other potential outcomes; (2) collect real-time information on individuals' experiences in real-life; and (3) inform policy decisions in important ways in relation to the design and management of public spaces and public transportation, and community safety practices.

\section{Utility of EMAs for collecting context-specific information about fear of crime and perceived risk of crime}

The results from our pilot study show that fear of crime and perceived risk levels are affected by many context-specific factors. Fear of crime and perceived risk levels can be different at different times, different modes of transit, and different stages of travel and both can be strongly influenced by perceived level of incivilities and experiences of crowdedness in and around public transit. With the exception of recent studies by Chataway et al. (2017) and Chataway et al. (2019), no other studies have systematically collected real-time context specific data on correlates of fear of crime and perceived risk of crime. The results from these studies and our study suggest that EMAs can be used successfully in the study of fear of crime to identify the dynamic nature of fear of crime and perceived risk of victimization in individuals' natural environments. 


\section{Measurement of fear of crime and perceived risk of crime, and other outcomes}

The results from our pilot study show that, as also supported by recent work by Chataway et al., (2017) and Chataway et al. (2019), EMAs coupled with smartphone technology can advance not only fear of crime research but also any study of human behaviors, experiences, and emotions in individuals' natural environments.

\section{Implications and recommendations for future research and practice}

The methodology of our study can be relevant for researchers and practitioners in many fields including but not limited to Criminology, Transportation, Urban Planning, Architecture, Sociology, Public Health, and Peace Engineering. As discussed in the limitations section, owing to the small number of participants in our study, we were not able to use our respondents as our unit of analysis. Future research with larger samples using the EMA methodology can consider how individual effects play into context-specific correlates of perceptions, emotions, and behaviors of individuals in real-time settings. Furthermore, future studies on the construct validity of measurements from EMAs can drastically extend the existing literature on the measurement of fear of crime and perceived risk of crime.

Our pilot study showed that EMAs can provide critical information on spatiotemporal triggers of fear of crime in public transit settings and other public settings. This insight can inform policy decisions in important ways in relation to the design and management of public spaces and public transportation, and community safety practices. Time and place-relevant information on fear of victimization can guide practitioners to apply the principles of evidence-based crime prevention strategies such as situational crime prevention and crime prevention through environmental design to respond to fear, risk, and victimization incidents to reduce or remove the triggers for these experiences. Furthermore, EMAs can be used to elicit context-specific feedback from transit users for improving public transit and public spaces. Public transit users' safety needs might be different at different stages of their journey and different design, management, and staffing issues in and around public transit can contribute to a heightened sense of fear of crime and perceived risk of crime. This requires a comprehensive and holistic response strategy that involves practitioners from inside and outside of public safety to reduce individuals' fear and to motivate their use of public transit options and public spaces.

Researchers in the field of Criminology and other fields should more effectively utilize smartphone technology and EMAs to expand upon the literature on various topics in human geography including but not limited to fear of crime and perceptions of safety at various places. This can provide local policymakers and practitioners with invaluable information on physical and social determinants of 
individuals' activities in their natural environments and, in turn, help them formulate effective strategies to respond to a variety of issues based on empirically valid data.

\section{Limitations of the study}

Our study had its own limitations and these limitations should inform the future research on fear of crime and EMAs. First, we completed the pilot testing of our methodology with a convenience sample of six respondents over 4 days. Second, 90 percent of the EMAs in our pilot study were reported during the daytime hours. Third, at the beginning of our study, we provided training to our pilot participants acknowledging this kind of a training might bias our results. We decided to develop this training during our conferral with our project's Institutional Review Board because this was a first kind of an EMA study to be implemented in our study setting and we wanted to minimize the potential harm to the pilot participants. Our training included: (1) an informed consent protocol; (2) information about how to use the app; (3) the routes of observation around the BRT stops; (4) a short psychological counseling session on the risks that might be associated with participating in the study; (5) a short session on legal requirements of reporting crime while participating in the study; (6) a practice session to collect data with the app; and (7) a custom pamphlet including information on whom to contact if respondents run into issues during data collection including the contact information of project staff, the project's legal and psychological counsellors, and support services available through local NGOs.

We suggest the following remedies to address our study limitations for future research. First, during a larger scale project, having a larger study sample that is representative of the study population can allow researchers to (1) use respondents as the units of analysis to correlate individuals' characteristics/past experiences with real-time fear and (2) to increase the external validity of their study findings. Second, as observed in our study and as supported by the literature (see Chataway et al. 2017), EMAs can make participants more alert to and more observant of their surroundings. Future and large-scale implementation of EMAs should consider the safety of the individuals involved in data collection and the potential bias that can be introduced by providing safety training to respondents in a study. One way to troubleshoot this kind of a bias can be to accept the data from the first couple of days to a week of a longer data collection effort as a burn in period and to discard such data.

\subsection{Conclusion}

As explained earlier in detail, our study has its own limitations. Yet, we still believe our study makes significant contributions to the measurement of context-specific fear and perceived risk of crime (and other context-specific experiences) in real time as people go about their lives. We showcased through 
our study that asking people about their fear of crime and perceived risk of crime in different stages of their public transit journeys provides a unique opportunity to capture environment-specific correlates of fear and perceived risk including individuals' perceptions of incivility, experience of crowdedness, and time effects. Although our study focuses on a specific application of EMAs to capture fear of crime and perceived risk of victimization, this pilot study demonstrates that smart device technology coupled with EMAs can be a promising data collection tool to capture better measures of behaviors, experiences, and emotions in individuals' natural environments. Understanding the contextspecific correlates of behaviors, experiences, and emotions can provide practitioners in the field of criminology and other fields with additional insight for more effective strategies to respond to triggers of fear.

\subsection{Acknowledgments}

We acknowledge the support of the International Development Research Centre (IDRC), the Hewlett Foundation, the Department for International Development (DFID), the WorldBank Group (WBG) and the Sexual Violence Research Initiative (SVRI) for the work that underlies this paper. We would like also to thank Dr. Mangai Natarajan, Arslan Ihsan, Assad Sarwar, Fatima Abbas, Alexandra Ricks, and Emily Reimal for their continuous support with our research activities and the editors of this book and anonymous peer-reviewers for their valuable feedback.

\section{References}

Badiora, A. I., Ojewale, O. S., \& Okunola, O. H. (2015). Perceived risk and fear of crime in public transport nodes: the experience from Nigerian transit environment. International Journal of Criminal Justice Sciences, 10, 139-151.

Burgess, J. (2002). 'But is it worth taking the risk?': how women negotiate access to urban woodland: a case study. In R. Ainley (Ed.), New Frontiers of Space, Bodies and Gender. London: Routledge, 133-146.

Chataway, M. L., Hart, T. C., \& Bond, C. (2019). The social-psychological process of fearing crime: developing and testing a new momentary model of victimisation worry. Australian \& New Zealand Journal of Criminology, 52(4), 462-482.

Chataway, M. L., Hart, T. C., Coomber, R., \& Bond, C. (2017). The geography of crime fear: a pilot study exploring event-based perceptions of risk using mobile technology. Applied Geography, 86, 300-307.

Cozens, P., Neale, R., Whitaker, J., \& Hillier, D. (2003). Managing crime and the fear of crime at railway stations-a case study in South Wales (UK). International Journal of Transport Management, 1, 121-132.

Farrall, S. D., Jackson, J., \& Gray, E. (2009). Social Order and the Fear of Crime in Contemporary Times. Oxford, UK: Oxford University Press.

Hale, C. (1996). Fear of crime: a review of the literature. International Review of Victimology, 4, 79-150.

Herbert, D., \& Davidson, N. (1994). Modifying the built environment: the impact of improved street lighting. Geoforum, 25, 339-350. 
Innes, M., \& Jones, V. (2006). Neighbourhood Security and Urban Change: Risk, Resilience and Recovery. York, UK: Joseph Rowntree Foundation.

Irvin-Erickson, Y., Malik, A. A., Kamiran, F., \& Natarajan, M. (2020). Utility of ecological momentary assessments to collect data on fear of crime. International Journal of Comparative and Applied Criminal Justice. Online first DOI: 10.1080/01924036. 2020.1719532, 1-13.

Koskela, H., \& Pain, R. (2000). Revisiting fear and place: women's fear of attack and the built environment. Geoforum, 31, 269-280.

LaGrange, R. L., Ferraro, K. F., \& Supancic, M. (1992). Perceived risk and fear of crime: role of social and physical incivilities. Journal of Research in Crime and Delinquency, $29,311-334$.

Lindgren, T., \& Nilsen, M. R. (2012). Safety in residential areas. Tijdschrift voor economische en sociale geografie, 103, 196-208.

Liska, A. E., Lawrence, J. J., \& Sanchirico, A. (1982). Fear of crime as a social fact. Social Forces, 60, 760-770.

Lorenc, T., Clayton, S., Neary, D., Whitehead, M., Petticrew, M., Thomson, H., Cummins, S., Sowden, A., \& Renton, A. (2012). Crime, fear of crime, environment, and mental health and wellbeing: mapping review of theories and causal pathways. Health \& Place, 18, 757-765.

Lorenc, T., Petticrew, M., Whitehead, M., Neary, D., Clayton, S., Wright, K., Thompson, H., Cummins, S., Sowden, A., \& Renton, A. (2013). Fear of crime and the environment: systematic review of UK qualitative evidence. BMC Public Health, 13, 496.

Nasar, J. L., \& Jones, K. M. (1997). Landscapes of fear and stress. Environment and behavior, 29, 291-323.

Pain, R. H. (1997). Social geographies of women's fear of crime. Transactions of the Institute of British Geographers, 22, 231-244.

Pain, R. (2000). Place, social relations and the fear of crime: a review. Progress in Human Geography, 24, 365-387.

Pain, R., \& Townshend, T. (2002). A safer city centre for all? Senses of community safety in Newcastle upon Tyne. Geoforum, 33, 105-119.

Painter, K. (1989). Crime Prevention and Public Lighting with Special Focus on Women and Elderly People. London: Middlesex Polytechnic.

Patterson, A. H. (1985). Fear of crime and other barriers to use of public transportation by the elderly. Journal of Architectural and Planning Research, 2(4), 277-288.

Raento, M., Oulasvirta, A., \& Eagle, N. (2009). Smartphones: an emerging tool for social scientists. Sociological Methods \& Research, 37, 426-454.

Skogan, W. G., \& Maxfield, M. G. (1981). Coping with Crime: Individual and Neighborhood Reactions. Beverly Hills, CA: Sage Publications.

Vrij, A., \& Winkel, F. W. (1991). Characteristics of the built environment and fear of crime: a research note on interventions in unsafe locations. Deviant Behavior, 12, 203-215.

Warr, M. (1990). Dangerous situations: social context and fear of victimization. Social Forces, 68, 891-907.

Waters, J., Neale, R., \& Mears, K. (2007). Design and Community Regeneration: Investigating Personal Safety Concerns of Older People in Socio-economically Deprived Communities in South Wales. Pontypridd: University of Glamorgan.

Wilson, J. Q., \& Kelling, G. L. (1982). Broken windows. Atlantic Monthly, 249, 29-38. 